Tropical Journal of Pharmaceutical Research March 2017; 16 (3): 563-572

ISSN: $1596-5996$ (print); 1596-9827 (electronic)

(C) Pharmacotherapy Group, Faculty of Pharmacy, University of Benin, Benin City, 300001 Nigeria.

All rights reserved.

Available online at http://www.tjpr.org

Original Research Article

http://dx.doi.org/10.4314/tjpr.v16i3.9

\title{
Anti-obesity effect of phenylcoumarins from two Calophyllum spp in 3T3-L1 adipocytes
}

\author{
Siroshini Thiagarajan ${ }^{1}$, Fui-Lu Yong ${ }^{2}$, Hemaroopini Subramaniam², Vivien Yi- \\ Mian Jong ${ }^{3}$, Chan-Kiang Lim ${ }^{2}$ and Yee-How Say ${ }^{1 *}$ \\ ${ }^{1}$ Department of Biomedical Science, ${ }^{2}$ Department of Chemical Science, Faculty of Science, Universiti Tunku Abdul Rahman \\ (UTAR) Kampar Campus, Kampar, Perak, ${ }^{3}$ Centre for Applied Sciences, Faculty of Applied Sciences, Universiti Teknologi \\ MARA Samarahan Campus 2, Kota Samarahan, Sarawak, Malaysia
}

*For correspondence: Email: sayyh@utar.edu.my; Tel: +605-4688888 ext. 4505; Fax: +605-4661676

Received: 16 November 2016

Revised accepted: 17 February 2017

\begin{abstract}
Purpose: To evaluate the anti-obesity effects of five compounds isolated from Calophyllum andersonnii and Calophyllum sclerophyllum, viz, friedelin (CP1), friedelinol (CP2), isodispar B (CP3), 5,7-dihydroxy6-(3-methybutyryl)-4-phenylcoumarin (CP4) and 5,7-dihydroxy-6-(2-methybutyryl)-4-phenylcoumarin (CP5) in 3T3-L1 mouse pre-adipocytes.

Methods: Maximum non-toxic doses (MNTDs) of CP1 - CP5 were obtained by conducting 3-(4,5dimethylthiazol-2-yl)-2,5-diphenyltetrazolium bromide (MTT) assay. Intracellular lipid droplet accumulation was determined by Oil Red O (ORO) staining. The effects of CP1 - 5 on the expression of adipogenesis transcriptional factors, namely, C/ebpa, Ppary1, aP2 and on cellular glucose uptake and adipokine (adiponectin, leptin, resistin) secretion were assessed by commercial colorimetric and ELISA kits, respectively.

Results: MNTDs for CP1-CP5 were 3.0, 1.4, 1.0, 29.0 and 25.0 $\mu M$, respectively. 3T3-L1 cells treated with CP1 - CP3 showed increased lipid accumulation $(p<0.05)$ and decreased glucose uptake $(p<$ 0.05), compared with untreated cells; cells treated with CP4 and CP5 had opposite effects. Cells treated with CP4 and CP5 also showed downregulated Ppary1, C/ebpa and aP2 expression ( $p<0.05)$, compared with untreated cells. The anti-adipogenic property exerted by CP4 and CP5 manifested as increased secretion of adiponectin as well as reduced leptin and resistin levels.

Conclusion: CP4 and CP5 isolated from Calophyllum sclerophyllum show promising anti-obesity properties, and could serve as candidate hits for further investigation at in vivo level to provide additional mechanistic evidence.
\end{abstract}

Keywords: Phenylcoumarin, Calophyllum, Adipogenesis, Adipocyte, Adipokine, Obesity

Tropical Journal of Pharmaceutical Research is indexed by Science Citation Index (SciSearch), Scopus, International Pharmaceutical Abstract, Chemical Abstracts, Embase, Index Copernicus, EBSCO, African Index Medicus, JournalSeek, Journal Citation Reports/Science Edition, Directory of Open Access Journals (DOAJ), African Journal Online, Bioline International, Open-J-Gate and Pharmacy Abstracts

\section{INTRODUCTION}

The genus Calophyllum, commonly known as "bintangor" or "penaga" in Malay, is a large group of tropical trees made up of around 200 different species [1]. Numerous Calophyllum species have been used in folk medicine. In Malaysia, the seed oil is used as a remedy for ulcer and rheumatism ailments. Moreover, Dweck and Meadows [2] reported the wound-healing property of Calophyllum seed oil after applying on scars. An infusion of the leaves is used to treat inflamed eyes.

Further pharmacological research on this genus has further revealed a variety of biological activities exhibited by these plants, such as antiHIV, antibacterial, antimalarial, antioxidant, 
antitumor-promoting, and cytotoxic activities [3]. These biological activities have been attributed to phytochemicals such as xanthones, coumarins, chomanones (flavonoids, biflavonoids), terpenes and steroids [3].

Isolation of phytochemicals from Calophyllum andersonnii and Calophyllum sclerophyllum (native in the jungle of Landeh, Sarawak, Borneo Malaysia) yielded two classes, namely triterpenoids (friedelin, freidelinol) and coumarins (isodispar B, 5,7-Dihydroxy-6-(3-methybutyryl)-4phenylcoumarin and 5,7-Dihydroxy-6-(2methybutyryl)-4-phenylcoumarin)[4]. These phytochemicals could have potential adipogenic modulatory effects, as previous studies have shown that friedelin and freidelinol isolated from other plants have pro-adipogenic effects $[5,6]$ while esculetin, a coumarin, has anti-adipogenic effect $[7,8]$.

Therefore, the objective of this study was to investigate if the five triterpenoids and coumarins above would have the same pro-/anti-adipogenic effects on a differentiated mouse pre-adipocyte cell line, 3T3-L1. Adipogenic parameters assessed included intracelluar lipid droplet accumulation, glucose uptake, gene expression of adipogenic transcription factors and secretion of adipokines.

\section{EXPERIMENTAL}

Plant, isolation and characterization of compounds

Triterpenoids - friedelin (compound 3) and friedelinol (compound 11) were isolated from Calophyllum andersonnii, while coumarins isodispar B (compound 1), 5,7-Dihydroxy-6-(3methybutyryl)-4-phenylcoumarin (compound 2) and 5,7-Dihydroxy-6-(2-methybutyryl)-4phenylcoumarin] were isolated from Calophyllum sclerophyllum [4] The detailed steps involved in the isolation and characterization of the compounds used in this study are as described previously [4]. Figure 1 shows the structure, codes and molecular weights of the five compounds.

\section{Cell culture}

Mus musculus mouse fibroblast cell line 3T3-L1 (ATCC $^{\circledR}$ CL-173'M) was obtained from the American Type Culture Collection (Manassas, VA, U.S.A.). Methods to differentiate 3T3-L1 preadipocytes were achieved according to ATCC protocol. Seeded cells were maintained in preadipocyte expansion medium [90 \% Dulbelcco's Modified Eagle's Medium (DMEM; Thermo Fischer Scientific PA, USA),

\section{Triterpenoids}

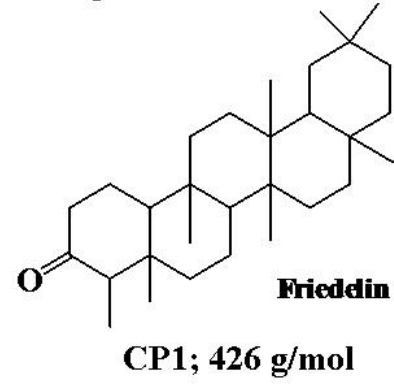

Coumarins<smiles>CC(C)CC(=O)c1c(O)cc(O)c2c(-c3ccccc3)cc(=O)oc12</smiles>

CP3; $338 \mathrm{~g} / \mathrm{mol}$

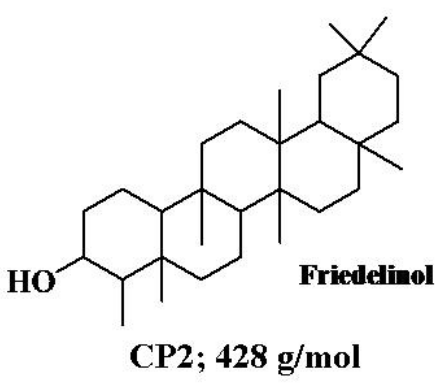<smiles>CC(C)CC(=O)c1c(O)cc2oc(=O)cc(-c3ccccc3)c2c1O</smiles>

5,7-Dihydroxy-6 (3-methylbutyry) 4-phenylcoumarin

CP4; $338 \mathrm{~g} / \mathrm{mol}$<smiles>CCC(C)C(=O)c1c(O)cc2oc(=O)cc(-c3ccccc3)c2c1O</smiles>

5,7-Dihydroxy-6-(2-methylbutyryl)4 phenylcoumarin

CP5; $338 \mathrm{~g} / \mathrm{mol}$

Figure 1: Structure, molecular weight $(\mathrm{g} / \mathrm{mol})$ and codes of five selected compounds used in this study 
$10 \%$ Fetal Bovine Serum (FBS; Sigma-Aldrich, $\mathrm{MO}$, USA)] by incubating them at $37^{\circ} \mathrm{C}$ in a $5 \%$ humidified $\mathrm{CO}_{2}$ incubator for $48 \mathrm{~h}$ until $100 \%$ confluence was achieved (day 0). To induce differentiation, cells were incubated with differentiation medium [90 \% DMEM, $10 \%$ FBS, $0.5 \mathrm{mM}$ 3-isobutyl-1-methylxanthine (Merck KGaA, Germany), $0.25 \mu \mathrm{M}$ dexamethasone (Merck KGaA, Germany), $1 \mu \mathrm{g} / \mathrm{mL}$ insulin (Nacalai Tesque, Japan) and $2 \mu \mathrm{M}$ rosiglitazone (Nacalai Tesque, Japan)] for $72 \mathrm{~h}$ (day 3). Cells were then maintained in adipocyte maintenance medium (90\% DMEM, $10 \%$ FBS and $1 \mu \mathrm{g} / \mathrm{mL}$ insulin) for another 2 d (day 5), which was subsequently changed every $2 \mathrm{~d}$. At day 10 , the cells were fully differentiated after induction and subsequent bioassays were performed.

\section{Determination of maximum non-toxic dose (MNTD)}

A total of 2500 3T3-L1 pre-adipocytes cells/well were plated in 96-well plates. At $70 \%$ confluence, the cells were treated with the test compounds $(0,1.875,3.75,7.5,15,30$ and 60 $\mu \mathrm{M})$, dissolved in dimethyl sulfoxide (DMSO). Cell viability was assessed by $3-(4,5-$ dimethylthiazol-2-yl)-2.5-diphenyltetrazolium

bromide (MTT) assay. The cells were incubated for $48 \mathrm{~h}$ at $37{ }^{\circ} \mathrm{C}$ in humidified $5 \% \mathrm{CO}_{2}$. After 48 $\mathrm{h}$, cells were rinsed twice with phosphate buffer saline (PBS). Twenty microliters of $5 \mathrm{mg} / \mathrm{mL}$ MTT (Bio Basic Canada Inc, Canada) stock solution were added to each well, further incubated at 37 ${ }^{\circ} \mathrm{C}$ for $4 \mathrm{~h}$, before the addition of $100 \mu \mathrm{L}$ DMSO to solubilize the purple formazan crystals. After 1 $h$ of incubation, the absorbance was measured at $570 \mathrm{~nm}$ using a microplate reader (M200 Tecan, Switzerland). A graph of percentage of toxicity against the $\log _{10}$ concentration of phytochemicals was plotted to determine the MNTD or $1 / 2$ MNTD of the compounds. MNTD was determined at the first $x$-intercept where the toxicity is $0 \%$, while $1 / 2$ MNTD was half of the MNTD selected. These dosages were then added together in the differentiation medium at day 0 of differentiation as described in 'Cell Culture'.

\section{Determination of intracellular lipid droplet accumulation}

Eight days (day 10) after the induction of differentiation, the cells were rinsed three times with PBS. After fixation with paraformaldehyde (Sigma-Aldrich, MO, USA) for $1 \mathrm{~h}$, the cells were rinsed with PBS and then stained with freshly diluted ORO solution [3 parts $0.5 \%$ ORO (R\&M Chemicals, UK) in isopropyl alcohol and 2 parts of water] for $30 \mathrm{~min}$. The cells were then rinsed twice with water and visualized and photographed using an inverted phase contrast microscope (TS100, Nikon Eclipse, Japan). ORO stain was dissolved in isopropyl alcohol for quantitative analysis, and absorbance at $520 \mathrm{~nm}$ was measured using a microplate reader (M200, Tecan, Switzerland).

\section{Glucose uptake assay}

Glucose uptake was measured using glucose uptake assay kit (Abnova, Taiwan) according to manufacturer's instructions. First, 3T3-L1 cells were plated in 96-well plate and differentiated, and at day 10 the differentiated cells were starved for $12 \mathrm{~h}$ without the addition of FBS to the basic medium. The cells were then treated with insulin (100 nM), metformin (1 mM; SigmaAldrich, MO, USA), MNTDs of CP1-CP5 and 2deoxyglucose (2-DG) (negative control), for $1 \mathrm{~h}$. Cellular 2-DG uptake was then measured by monitoring OD ratio increase at 570/610 using a microplate reader. The $\mathrm{OD}$ ratio for 2-DG (negative control) was normalised at $1000 \mu \mathrm{M}$.

\section{Measurement of adipokine concentration}

After treatments, conditioned media were collected and cells were then rinsed with ice-cold PBS twice and lysed with $10 \mu \mathrm{L}$ of lysis buffer [10 $\mathrm{mM}$ Tris/ $\mathrm{HCl}, \mathrm{pH} 7.8,100 \mathrm{mM} \mathrm{NaCl}, 0.5 \%(\mathrm{w} / \mathrm{v})$ sodium deoxycholate, $0.05 \%(\mathrm{v} / \mathrm{v})$ nonidet $-\mathrm{P} 40$, $10 \mathrm{mM}$ EDTA, $0.1 \mathrm{mM}$ PMSF] added with $1 \mu \mathrm{L}$ of protein inhibitor cocktail (Thermo Fischer Scientific PA, USA). Subsequently, concentrations of mouse leptin, resistin and adiponectin in the conditioned medium and cell lysates were determined using commercial ELISA kits (CUSABIO, China) according to manufacturer's instructions. Protein concentrations of media and cell lysates were also measured by bicinchoninic acid protein assay kit (Thermo Fischer Scientific PA, USA) and adipokine concentrations were normalized per total extracted proteins.

\section{Determination of gene expression of adipogenesis markers}

The gene expression of three common adipogenesis markers namely mouse nuclear receptor peroxisome proliferator-activated receptor gamma 1 (Ppary1), CCAAT/enhancer binding protein-alpha (C/ebpa), and adipocyte fatty acid-binding protein $(a P 2)$ was assessed by semi-quantitative reverse transcriptionpolymerase chain reaction (RT-PCR). Total RNA was extracted from the 3T3-L1 adipocyte cells using EZ 10 Spin Column animal total RNA extraction kit (Bio Basic Canada Inc., Canada) according to manufacturer's instructions. RNA 
purity and concentration were determined using a nanospectrophotometer (IMPLEM, Germany) at absorbance of 260 and $280 \mathrm{~nm}$. The integrity of total RNA extracted was assessed by using 1 $\%(w / v)$ agarose gel electrophoresis and denaturing agent formamide. The primer sequences for RT-PCR were adopted from $[8,9]$. RT-PCR was performed using Realhelix ${ }^{{ }^{\mathrm{M}}}$ RTPCR Kit (Nanohelix, Korea) according to manufacturer's instructions on Bio-Rad CFX-96T RT-PCR machine following this protocol: 1 cycle of cDNA synthesis at $55^{\circ} \mathrm{C}$ for $50 \mathrm{~min} ; 1$ cycle of initial-denaturation at $95^{\circ} \mathrm{C}$ for $15 \mathrm{~min}$; 30 cycles of denaturation at $95{ }^{\circ} \mathrm{C}$ for $20 \mathrm{~s}$, annealing at 53, 57, 57 and $62^{\circ} \mathrm{C}$ for C/ebpa, Ppary1, aP2, $\beta$ actin, respectively, for $40 \mathrm{~s}$ and extension at 72 ${ }^{\circ} \mathrm{C}$ for $40 \mathrm{~s}$ and a final cycle of post extension at $72{ }^{\circ} \mathrm{C}$ for $5 \mathrm{~min}$. PCR products were resolved by $1.8 \%$ agarose gel electrophoresis, stained with Gel Red ${ }^{\circledR}$ dye (Biotium, CA, USA) and visualized with BIO-RAD Gel Doc image analysis software (BIO-RAD Laboratories Inc., CA, USA). Densitometry was performed using $\mathrm{NIH}$ Image $\mathrm{J}$ software.

\section{Statistical analysis}

The results are expressed as mean \pm standard error of the mean (SEM) of at least two independent experiments performed in at least triplicate, unless otherwise stated. Statistical analysis was performed using Student's $t$-test for comparison between two means using IBM SPSS Statistics software version 16.0 (IBM, NY, USA). A $p$-value $<0.05$ was considered as statistically significant.

\section{RESULTS}

\section{MNTD and $1 / 2$ MNTD of the compounds}

In the graph of cytotoxicity percentage in 3T3-L1 pre-adipocytes against log CP1-CP5 concentrations (Figure 2), the percentage of cytotoxicity for CP1, CP2 and CP5 showed fluctuations across concentrations while the percentage of cytotoxicity for CP3 and CP4 showed an increasing trend across concentrations.. However, cell death was not evident at concentrations below $3.75 \mu \mathrm{M}$, for CP1 and CP2; and at concentrations below 30 $\mu \mathrm{M}$ for CP3 and CP4 (Figure 2). MNTDs of CP1, CP2, CP3, CP4 and CP5 were 3.00, 1.44, 1.04, 29.0 and $25.0 \mu \mathrm{M}$, respectively, while their $1 / 2$ MNTDs were 1.50, 0.72, 0.52, 14.5 and 12.5 $\mu \mathrm{M}$, respectively. Overall, cytotoxicity of CP3 was the highest, and triterpenoids CP1 and CP2 were up to 20-folds more cytotoxic than phenylcoumarins CP4 and CP5.

\section{Phenylcoumarins inhibit intracellular lipid accumulation}

As an evidence of adipogenesis, copious ORO dye stained material accumulated in differentiated 3T3-L1 adipocytes (positive control) while no staining was detected in 3T3-L1 preadipocytes (negative control, Figure 3A). Compared to the negative control, cells treated with MNTDs and $1 / 2$ MNTDs of CP1 - CP3 showed higher accumulation of dye-stained material; CP4 and CP5 showed opposite effects (Figure 3A). A 100x magnification of the cells revealed larger adipocytes for CP1 - CP3 (indicating higher lipid droplet accumulation), while the opposite was observed for CP4 - CP5 (Figure 3B).

As shown in Figure $3 C$ and D, there was almost $50 \%$ less lipid accumulation in non-differentiated 3T3-L1 cells compared with differentiated cells. CP2 and CP3 at both doses significantly increased lipid accumulation compared with the positive control, while CP4 and CP5 at both doses decreased lipid accumulation of up to 0.7fold, albeit with statistical significance for the latter compound. Taken together, this implies that CP4 and CP5 would indeed attenuate adipocyte differentiation.

\section{Phenylcoumarins promote cellular glucose uptake in 3T3-L1 adipocytes}

As shown in Figure 4, treatment with insulin and with insulin + metformin (a type II diabetes mellitus drug) significantly increased cellular uptake of glucose in 3T3-L1 adipocytes. Treatment with MNTDs of CP1, CP2 and CP3 significantly decreased cellular glucose uptake compared with insulin-treated cells. On the other hand, CP4 and CP5 significantly stimulated cellular glucose uptake compared with insulintreated cells, but still the amount was still lesser than the synergistic effect of insulin + metformin (Figure 4). These indicate that phenylcoumarins CP4 and CP5 promote cellular glucose uptake in 3T3-L1 adipocytes, comparable with the effect of insulin.

\section{Phenylcoumarins inhibit adipogenesis by reducing gene expression of C/ebpa, Ppary1 and $a P 2$}

As shown in Figure 5, cells treated with CP1, CP2 and CP3 presented significant increases in the expression of adipocyte-specific transcriptional factors when compared with the untreated cells. 
Specifically, cells treated with CP2 had the highest expression of C/ebpa and Ppary1. Adipocyte specific transcriptional factor, $a P 2$ showed the highest expression when cells were treated with CP1, which was about $18 \%$ higher compared to the control (Figure 5). On the other hand, cells treated with CP4 and CP5 showed significant down-regulation of the expression of all three adipogenesis markers (Figure 5), implying that CP4 and CP5 attenuate adipocyte differentiation.

Phenylcoumarins from increase adiponectin and leptin secretion and decrease resistin secretion

As shown in Figure 6, differentiated 3T3-L1 adipocytes had increased secretions of
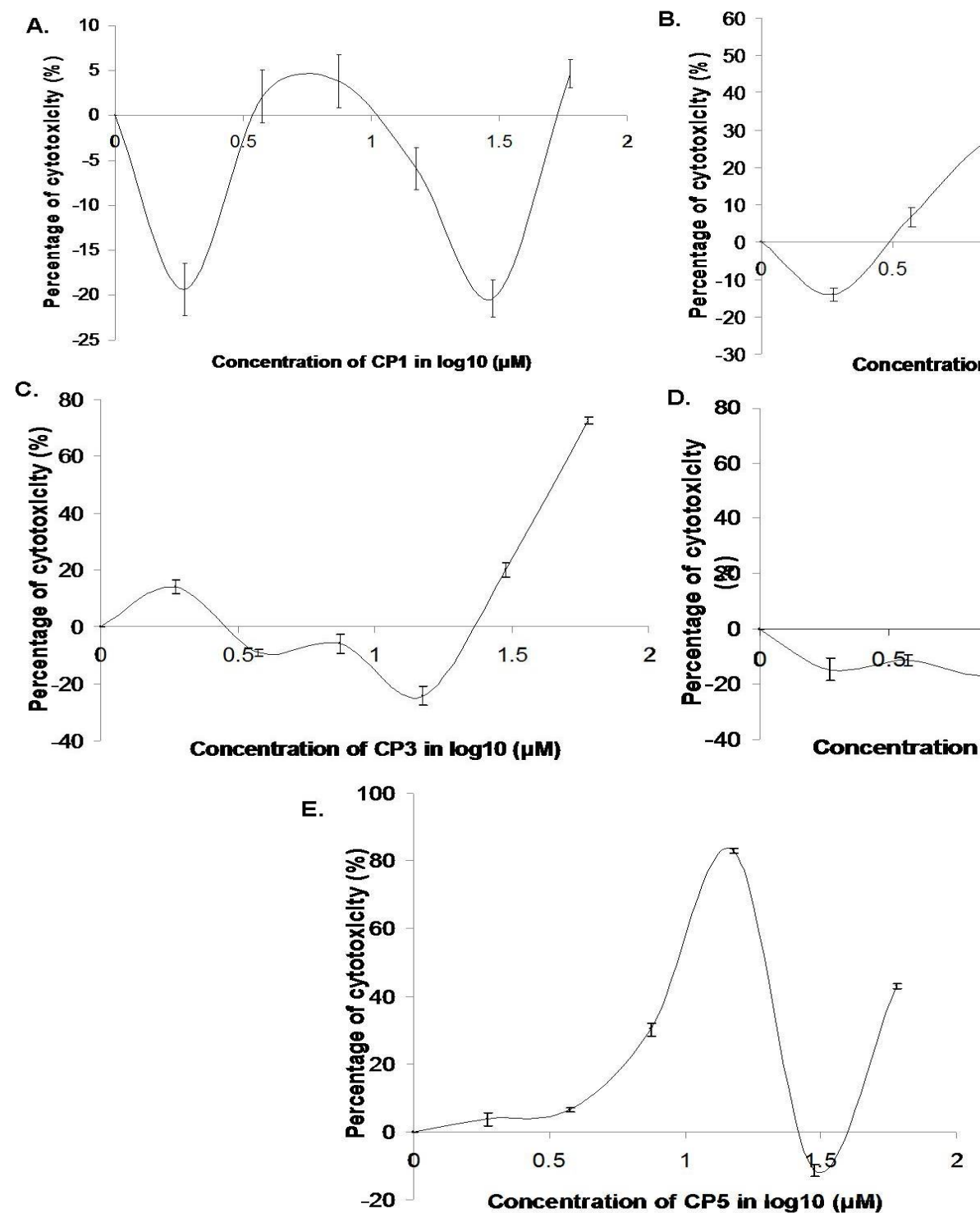

Figure 2: Maximum non-toxic dose (MNTD) and half maximum non-toxic dose (1/2 MNTD) of CP1 - CP5. Percentage of cytotoxicity of A. CP1; B. CP2; C. CP3; D. CP4; and E. CP4 on 3T3-L1 pre-adipocytes after incubation for $48 \mathrm{~h}$, in two-fold dilution method with the range of $60 \mu \mathrm{M}$ to $0 \mu \mathrm{M}$. MNTDs were determined where the graph intersects the $x$-axis, while $1 / 2$ MNTDs are half of the MNTDs obtained. Data are mean \pm SEM of three independent experiments performed in five replicates adiponectin, leptin and resistin compared with undifferentiated pre-adipocytes. Cells treated with $1 / 2$ MNTD CP5 had the highest amount of adiponectin secretion in conditioned medium, consistent with the lowest amount of intracellular adiponectin (Figure. 6A). Leptin secretion in conditioned medium was the highest in cells treated with CP2 (1/2MNTD), while the same cells had among the lowest intracellular leptin concentration (Figure 6B). Cells treated with CP4 had the highest intracellular leptin concentration. As for resistin, cells treated with CP3 (1/2MNTD) had the highest secretion (2.5 times higher) compared with differentiated adipocytes, while the lowest for cells treated with CP5 (MNTD) (Figure 6C). For intracellular resistin concentration, cells treated with CP1 (MNTD)

B. 60
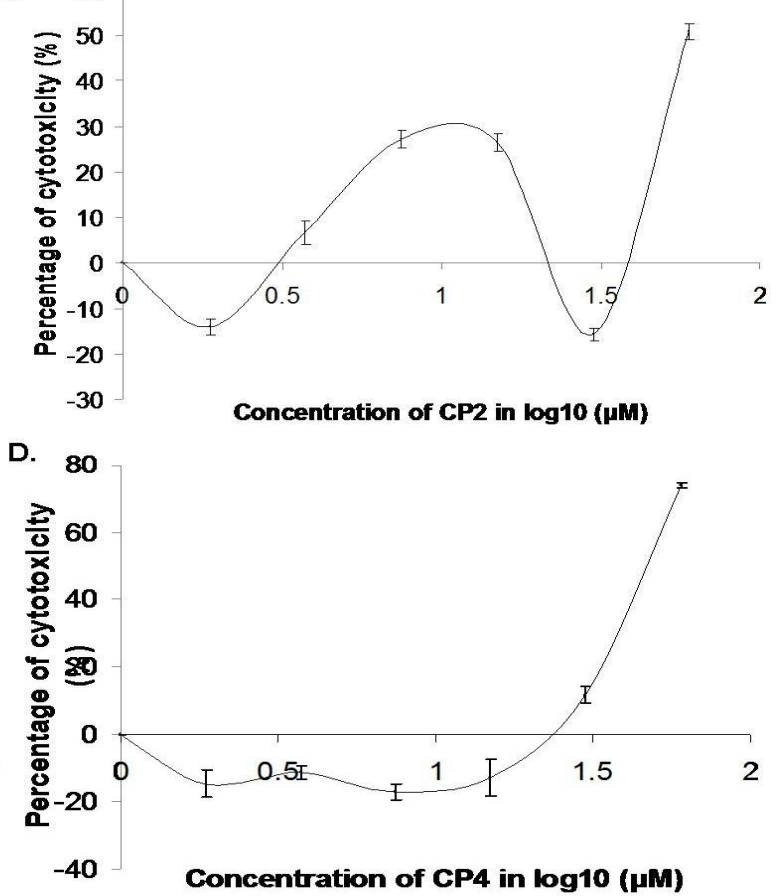


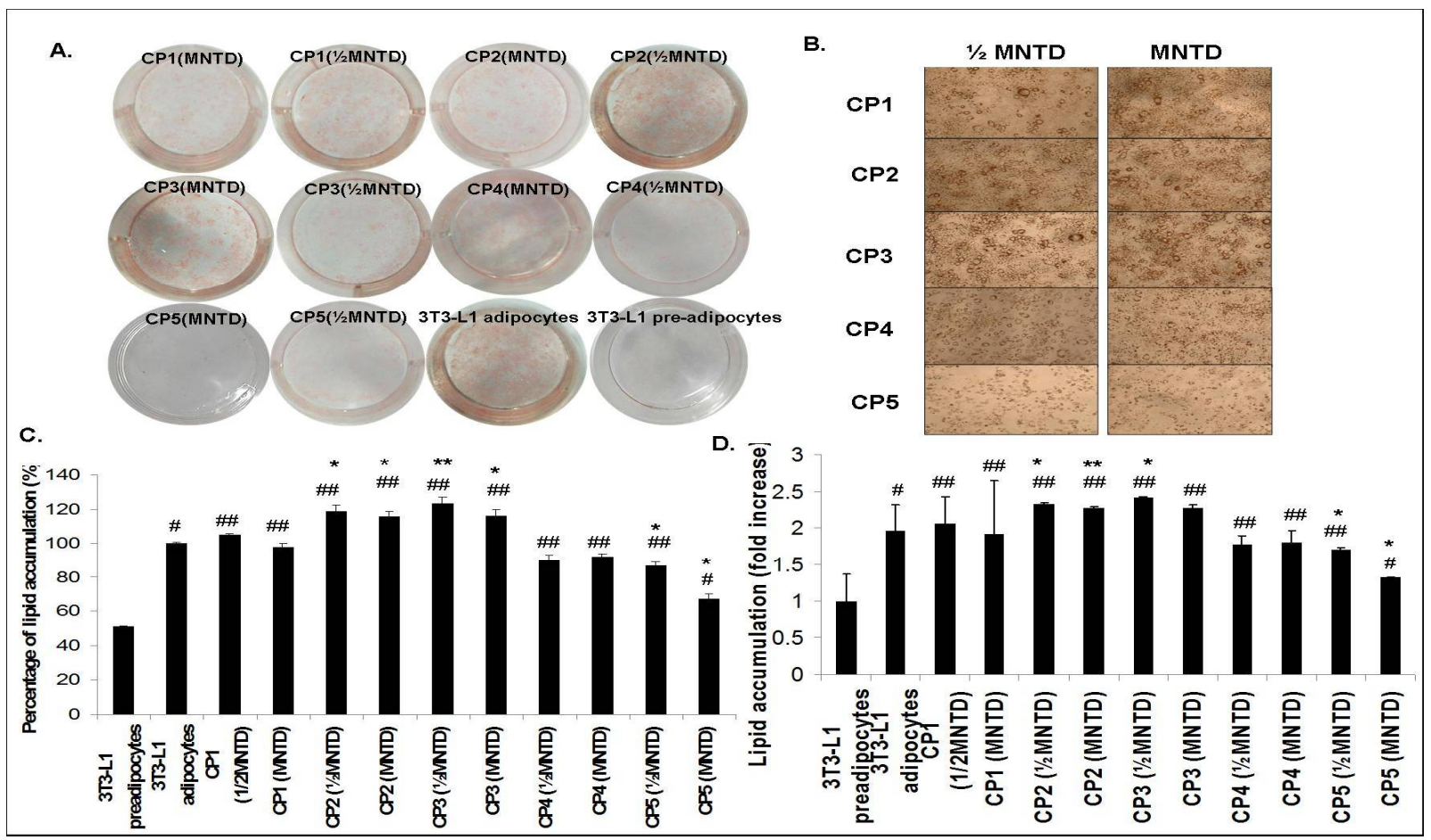

Figure 3: Intracellular lipid droplet accumulation in 3T3-L1 adipocytes. A = representative images after induction of differentiation with the differentiation cocktail along with the MNTDs and 1/2 MNTDs of CP1 - CP5. Red colour indicates ORO staining; the darker the stain, the higher the intracellular lipid droplet content. The amount of lipid accumulation were compared using the well of 3T3-L1 adipocytes (positive control); $B=$ Representative fields with 100x magnification of the wells in A for CP1 - CP5, showing the sizes of the adipocytes; $C=\%$ of lipid accumulation in 3T3-L1 treated cells and controls; D = Fold increases of lipid accumulation in 3T3-L1 treated cells and controls. Results are presented as mean \pm SEM $(n=3) ;{ }^{*} p<0.05 ;{ }^{\star \star} p<0.01$ compared with 3 T3-L1 adipocytes; ${ }^{\#} p<0.05 ;{ }^{\# \#} p<0.01$ compared to 3T3-L1 pre-adipocyte

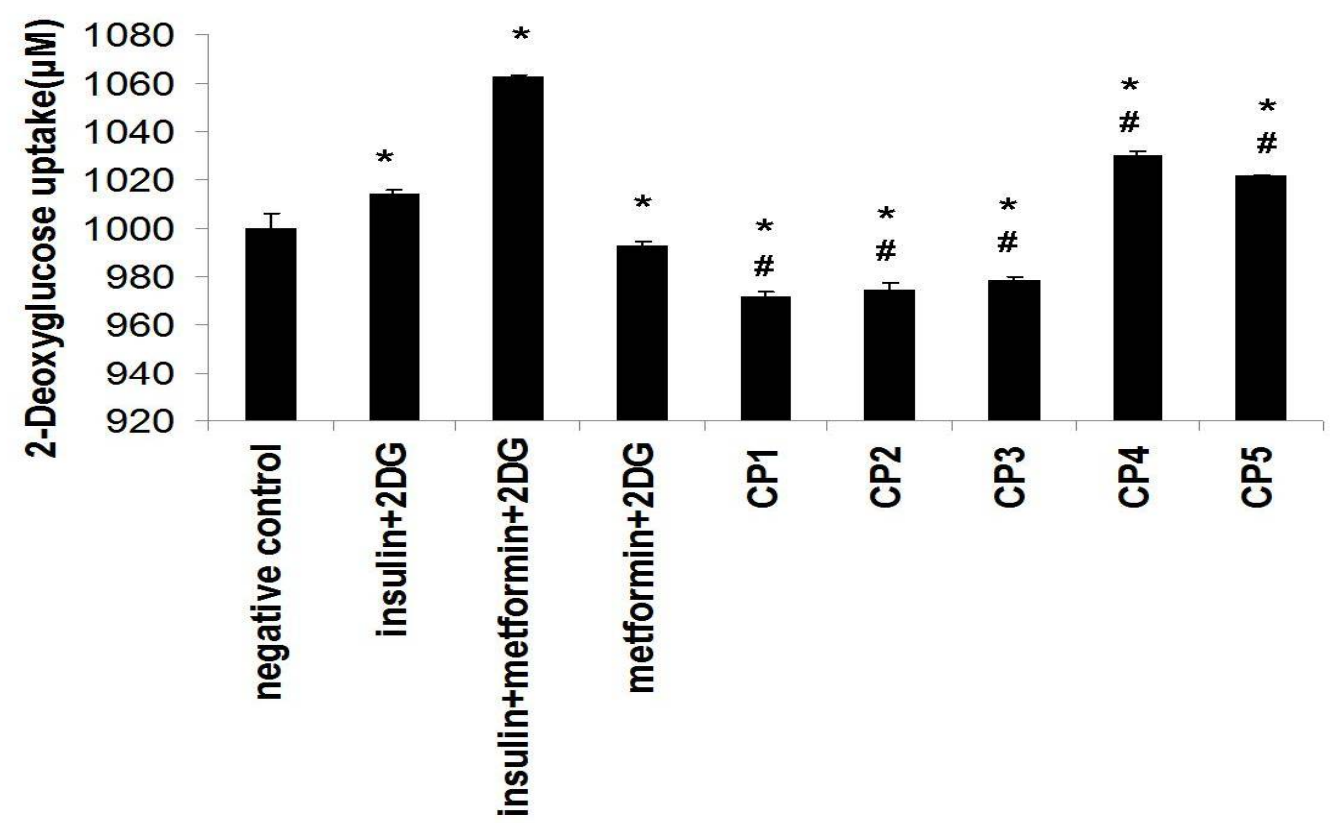

Figure 4: Effect of compounds CP1 - CP5 on cellular glucose uptake in 3T3-L1 adipocytes. Results are presented as mean \pm SEM, $(n=3) ;{ }^{*} p<0.05$ compared with the negative control; ${ }^{\#} p<0.05$ compared with insulin-treated cells (positive control) 


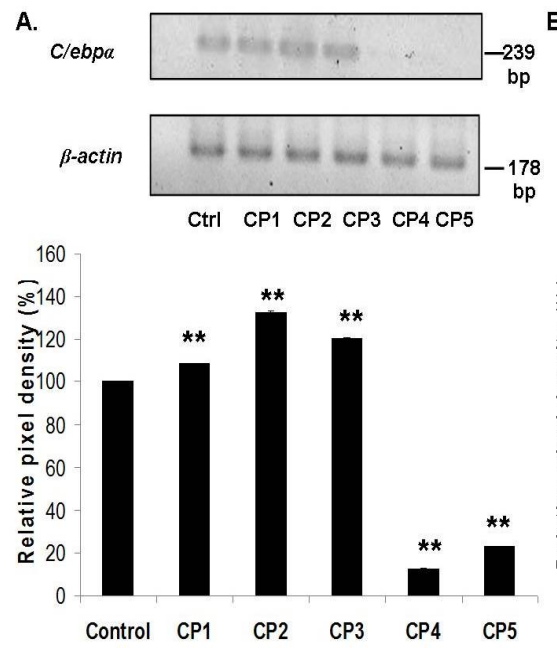

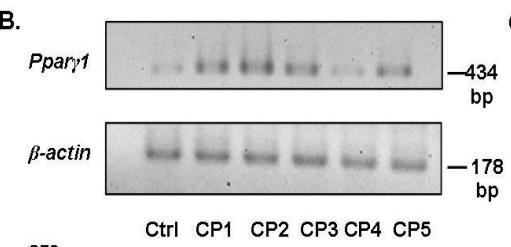

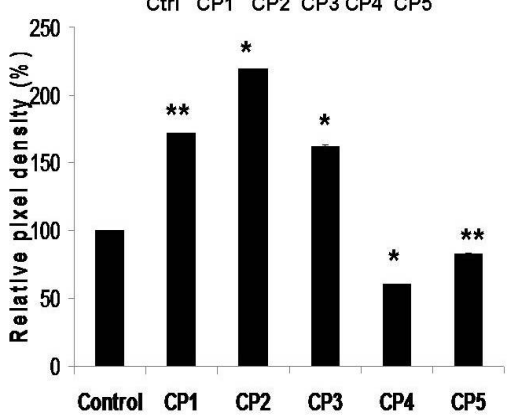

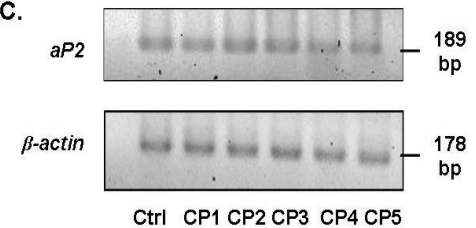

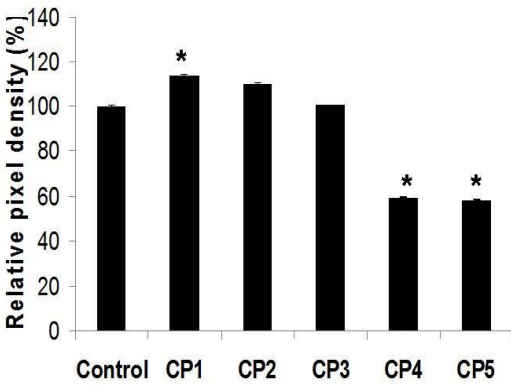

Figure 5: Effect of compounds CP1-CP5 on the expression of adipogenesis markers C/ebpa, Ppary1 and aP2 in 3T3-L1 adipocytes. Total RNA was extracted from differentiated 3T3-L1 adipocytes treated with MNTDs of CP1CP5 compounds and semi quantitative RT-PCR was performed for gene expression of A. C/ebpa; B. Ppary1 and C. aP2. Bar charts depict the densitometry as expressed as relative pixel density and expressed as ratio to $\beta$ actin (internal control not affected by compound treatment). Data are expressed as a percentage of control (set as $100 \%)$ and values represent mean $\pm \operatorname{SEM}(n=3)$ of three independent experiments; ${ }^{*} p<0.05 ;{ }^{* \star} p<0.01$ compared to the control

ADIPONECTIN

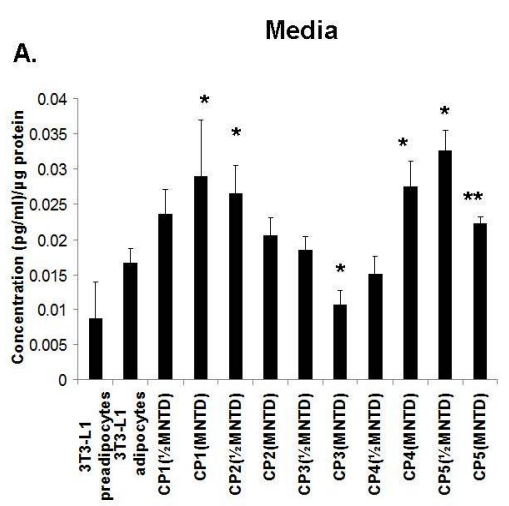

Lysates
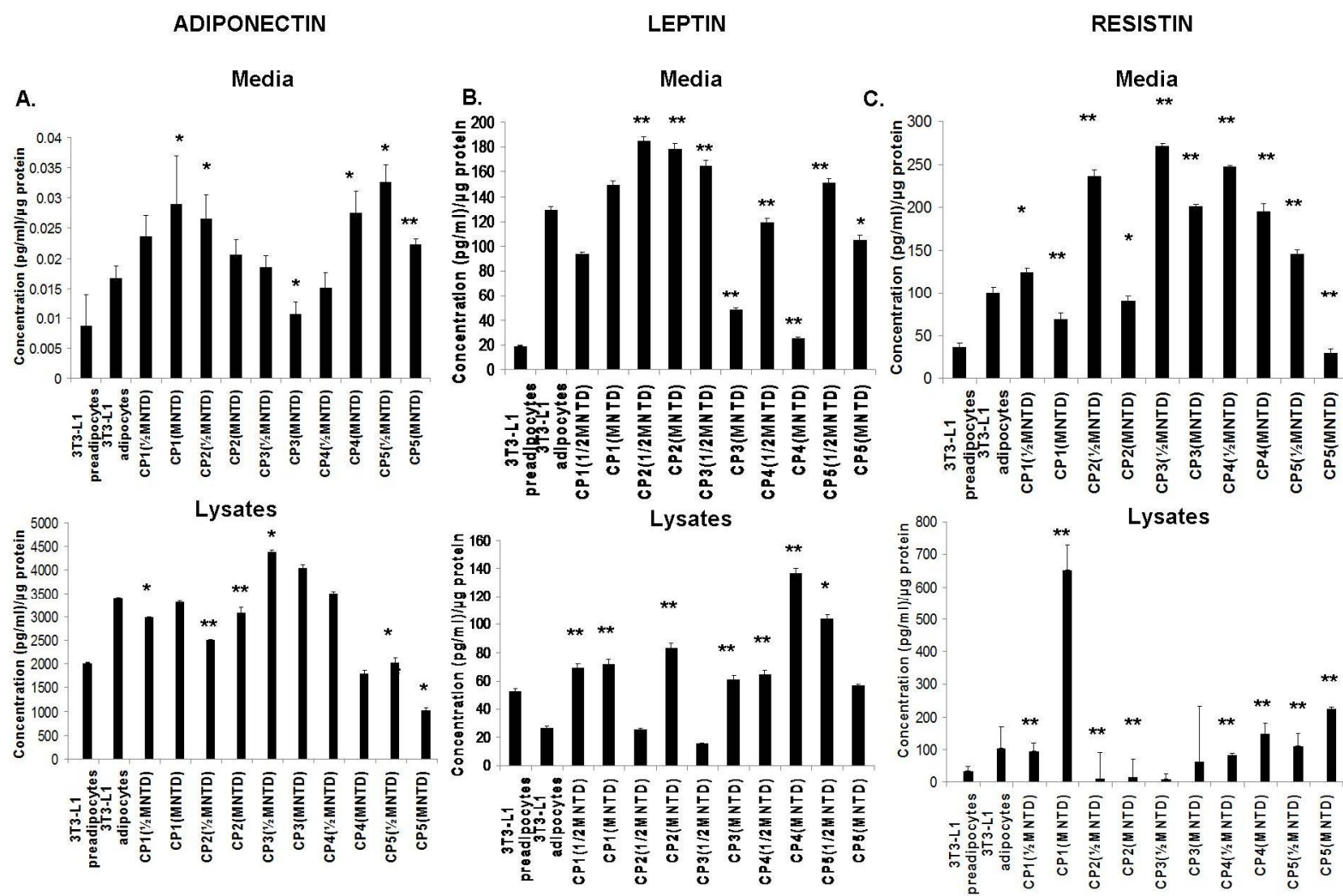

Figure 6: Extracellular secretions and intracellular concentrations of adiponectin, leptin and resistin treated or untreated with 1/2MNTD and MNTDs of CP1-CP5. Measurements of concentrations for A. Adiponectin; B. Leptin; C. Resistin, were conducted using commercial ELISA kits. Absorbance measurements were normalized per total extracted proteins. Data are expressed as concentration $(\mathrm{pg} / \mathrm{mL}) / \mu \mathrm{g}$ protein and values represent the mean \pm SEM $(n=3)$ of three independent experiments; ${ }^{*} p<0.05,{ }^{* \star} p<0.01$ compared to 3T3-L1 adipocytes 
showed 6.5 times higher level compared with differentiated adipocytes (Figure 6C).

\section{DISCUSSION}

Previously, it was shown that friedelin, a triterpenoid isolated from Garcinia prainiana, upregulated adipocyte differentiation and glucose uptake in 3T3-L1 adipocytes [6], while esculetin (a coumarin derivative), either naturally isolated from Fraxinus rhynchophylla [7] or chemicallysynthesized [8], has anti-adipogenic effect. In this study, we found that the anti-adipogenic and proglucose uptake activities of CP4 and CP5 are consistent with the reduced expression of adipogenesis markers Ppary1, C/ebpa, aP2, increased secretion of adiponectin and reduced secretion of leptin and resistin.

It is widely reported that adipogenesis can be inhibited or promoted by various natural compounds [6-8]. Two out of three coumarins that showed anti-adipogenic activity are CP4 and CP5. Isodipar B (CP3), also a coumarin, however showed pro-adipogenic effect. This may be due to the structural differences within the coumarins, as reported in [7]. There were differences in the moiety of R-group added to coumarin, the backbone of the phytochemicals $[6,10]$.

Methylbutyryl located on a different carbon might cause a difference in activity in adipocytes. In $\mathrm{CP} 3$, the R-group is located in C-8 of the coumarin backbone. These results therefore, suggest that methylbutyryl located in C-8 is important for exerting anti-adipogenic effect. For cells treated with CP1 and CP2, an induction in lipid accumulation was observed. Friedelin naturally isolated from Garcinia prainiana also exerted the same activity [6], albeit at a higher concentration of $10 \mu \mathrm{M}$ (vs. $3 \mu \mathrm{M}$ in our study).

Unlike friedelin from Garcinia prainiana which promoted cellular glucose uptake in 3T3-L1 adipocytes [6], our results showed the opposite effect. This discrepancy could be due to the higher dose used in our study. For the first time, we observed that treatment with $\mathrm{CP} 4$ and $\mathrm{CP} 5$ promoted 3T3-L1 adipocyte uptake of glucose, to the extent that it was even significantly higher than the positive control, insulin. Therefore, compounds CP4 and CP5 may imitate the action of insulin in stimulating cellular glucose uptake and it is speculated that these compounds may also reduce blood glucose level in vivo. Based on the above findings, it appears that our findings related to the effect of phenylcoumarins CP4 and CP5 on 3T3-L1 adipocytes were in agreement with two other reports $[12,13]$ stating that compound that inhibits adipocyte differentiation could also improve glucose uptake.

In this study, we also measured the gene expression of three common adipogenesis markers C/ebpa, Ppary1 and aP2 to see if their expression correlates with the adipocyte differention/lipid droplet accumulation as assessed by ORO staining. C/ebpa and Ppary activate transcriptional adipogenesis activity by binding to their genomic promoter region interchangeably [14]. Cells treated with CP1, CP2 and CP3 showed pro-adipogenic activity, by increasing Ppary1, C/ebpa and aP2 expression. Conversely, CP4- and CP5-treated cells showed a reduction in the expression of Ppary1, C/ebpa and $a P 2$. The findings are supported by previous studies which showed that the reduction in adipocyte differentiation and increase in cellular glucose uptake are also correlated with the downregulation of C/ebpa, Ppary1 and aP2 expression $[8,15]$.

Besides playing a role as an energy depot, the adipose tissue also secretes adipokines that are metabolic regulators. Three adipokines assessed in this study - adiponectin, leptin and resistin, modulate adipogenesis and are correlated with body mass index and total body fat [16]). Plasma levels of leptin and resistin has been shown to be proportional to body fat mass $[17,18]$, whereas plasma adiponectin level is negatively correlated with the percentage of body fat [19]. Therefore, we hypothesized that CP4 and CP5 compounds which show antiadipogenic/pro-glucose uptake effects would also show increased adiponectin and decreased leptin and resistin secretions in 3T3-L1 adipocytes. However, we found that CP1 - CP4 (MNTD) compounds produced mixed effects on the secretions of these adipokines, which do not correlate with their adipogenic/glucose uptake properties shown earlier. This phenomenon could be due to the unassessed complex signaling pathways that modulate the secretion of these adipokines and adipogenesis/glucose uptake independently. Nevertheless, CP5 (MNTD) consistently produced increased adiponectin and reduced leptin and resistin secretions, compared with untreated cells. Similarly, ginsenoside has been shown to reduce 3T3-L1 adipocyte lipid accumulation and increase adiponectin expression [20], while Lysimachia foenum-graecum treatment increased adiponectin level while decreasing leptin and resistin levels in the plasma of treated mice [21]. 


\section{CONCLUSION}

Friedelin and friedelinol isolated from Calophyllum andersonnii promote adipogenesis by increasing intracellular lipid droplet accumulation and expression of adipogenesisrelated genes including Ppary1, C/ebpa and aP2, and also by decreasing cellular glucose uptake in 3T3-L1 adipocytes. On the other hand, 5,7dihydroxy-6-(3-methybutyryl)-4-phenylcoumarin and 5,7-dihydroxy-6-(2-methybutyryl)-4-phenylcoumarin isolated from Calophyllum sclerophyllum show promising anti-obesity properties by attenuating adipogenesis (decreasing intracellular lipid droplet accumulation and expression of Ppary1, C/ebpa and $a P 2$ ), and also by increasing 3T3-L1 adipocyte glucose uptake. Last but not least, 5,7dihydroxy-6-(2-methybutyryl)-4-phenylcoumarin increases adiponectin and reduces leptin and resistin secretions from 3T3-L1 treated cells.

\section{DECLARATIONS}

\section{Acknowledgement}

This work was supported by a grant from UTAR Research Fund (no. IPSR/RMC/UTARRF/2013C2/L09).

\section{Conflict of Interest}

No conflict of interest associated with this work.

\section{Contribution of Authors}

The authors declare that this work was done by the authors named in this article and all liabilities pertaining to claims relating to the content of this article will be borne by them.

\section{Open Access}

This is an Open Access article that uses a funding model which does not charge readers or their institutions for access and distributed under the terms of the Creative Commons Attribution License (http://creativecommons.org/licenses/by 14.0) and the Budapest Open Access Initiative (http://www.budapestopenaccessinitiative.org/rea d), which permit unrestricted use, distribution, and reproduction in any medium, provided the original work is properly credited.

\section{REFERENCES}

1. Crane S, Aurore G, Joseph H, Mouloungui Z, Bourgeois $P$. Composition of fatty acids triacylglycerols and unsaponifiable matter in Calophyllum calaba I. Oil from guadeloupe. Phytochemistry 2005; 66: 1825-1831.

2. Dweck AC, Meadows T. Tamanu (Calophyllum inophyllum) - the African, Asian, Polynesian and Pacific Panacea. Int J Cosmetic Sci 2002; 24: 341-348.

3. Cechinel VF, Meyre-Silva C, Niero R. Chemical and pharmacological aspects of the genus Calophyllum. Chem Biodiv 2009; 6: 313-327.

4. Lim CK, Hemaroopini S, Gan SY, Loo SM, Low JR, Jong VYM, Soo HC, Leong CO, Mai CW, Chee CF. In vitro cytotoxic activity of isolated compounds from Malaysian Calophyllum species. Med Chem Res. 2016; 25: 1686-1694.

5. Lee I, Kim H, Youn U, Kim J, Min B, Jung $H, N a M$, Hattori $M$, Bae $K$. Effect of lanostane triterpenes from the fruiting bodies of Ganoderma lucidum on adipocyte differentiation in 3T3-L1 Cells. Planta Med 2010; 76: 1558-1563.

6. Susanti D, Amiroudine M, Rezali M, Taher M. Friedelin and lanosterol from Garcinia prainiana stimulated glucose uptake and adipocytes differentiation in 3T3-L1 adipocytes. Nat Prod Res 2013; 27: 417-424.

7. Shin E, Choi K, Yoo $H$, Lee C, Hwang B, Lee $M$. Inhibitory effects of coumarins from the stem barks of Fraxinus rhynchophylla on adipocyte differentiation in 3T3-L1 cells. Biol Pharm Bull 2010; 33: 1610-1614.

8. Kim $Y$, Lee J. Esculetin, a coumarin derivative, suppresses adipogenesis through modulation of the AMPK pathway in 3T3-L1 adipocytes. J Funct Foods 2015; 12: 509-515.

9. Nerurkar $P$, Lee $Y$, Nerurkar V. Momordica charantia (bitter melon) inhibits primary human adipocyte differentiation by modulating adipogenic genes. BMC Complement Altern Med 2010; 10: 34.

10. Song Y, Park H, Kang S, Jang S, Lee S, Ko Y, Kim G, Cho J. Blueberry peel extracts inhibit adipogenesis in 3T3-L1 cells and reduce high-fat diet-induced obesity. PLOS ONE 2013; 8: e69925.

11. Jain $P$, Joshi $H$. Coumarin: Chemical and pharmacological profile. J App Pharm Sci 2012; 2: 236240.

12. Anand S, Muthusamy V, Sujatha S, Sangeetha $K$, Bharathi RR, Sudhagar S, Poornima DN, Lakshmi B. Aloe emodin glycosides stimulates glucose transport and glycogen storage through PI3K dependent mechanism in $L 6$ myotubes and inhibits adipocyte differentiation in 3T3L1 adipocytes. FEBS Lett 2010; 584: 3170-3178.

13. Taher M, Mohamed AM, Tengku ZT, Susanti D, Ichwan $S$, Kaderi M, Ahmed Q, Zakaria Z. a-Mangostin improves glucose uptake and inhibits adipocytes differentiation in 3T3-L1 cells via PPARY, GLUT4, and leptin expressions. Evid Based Complement Altern Med 2015; 2015: 740238.

14. Lee J, Ge K. Transcriptional and epigenetic regulation of PPARY expression during adipogenesis. Cell Biosci 2014; 4: 29. 
15. Kowalska K, Olejnik A, Rychlik J, Grajek W. Cranberries (Oxycoccus quadripetalus) inhibit lipid metabolism and modulate leptin and adiponectin secretion in 3T3-L1 adipocytes. Food Chem 2015; 185: 383-388.

16. Makki K, Froguel P, Wolowczuk I. Adipose tissue in obesity-related inflammation and insulin resistance: cells, cytokines, and chemokines. ISRN Inflamm 2013; 2013: 139239.

17. Friedman J, Halaas J. Leptin and the regulation of body weight in mammals. Nature 1998; 395: 763-770.

18. Steppan CM, Bailey ST, Bhat S, Brown EJ, Banerjee RR, Wright CM, Patel HR, Ahima RS, Lazar MA. The hormone resistin links obesity to diabetes. Nature 2001; 409: $307-312$
19. Yamauchi T, Kamon J, Waki H, Terauchi Y, Kubota N, Hara K, Mori $Y$, Ide T, Murakami K, TsuboyamaKasaoka $N$, et al. The fat-derived hormone adiponectin reverses insulin resistance associated with both lipoatrophy and obesity. Nat Med 2001; 7: 941-946.

20. Yeo CR, Lee SM, Popovich DG. Ginseng (Panax quinquefolius) reduces cell growth, lipid acquisition and increases adiponectin expression in 3T3-L1 cells. Evid Based Complement Alternat Med 2011; 2011: 610625.

21. Seo JB, Choe SS, Jeong HW, Park SW, Shin HJ, Choi SM, Park JY, Choi EW, Kim JB, Seen DS, et al. Antiobesity effects of Lysimachia foenum-graecum characterized by decreased adipogenesis and regulated lipid metabolism. Exp Mol Med 2011; 43: 205-215. 